\title{
Treatment of Active Acne Vulgaris by Chemical Peeling Using TCA $35 \%{ }^{*}$
}

\author{
Khalifa E. Sharquie $^{1 \#}$, Adil A. Noaimi ${ }^{2}$, Entesar A. Al-Janabi ${ }^{3}$ \\ ${ }^{1}$ Scientific Council of Dermatology \& Venereology_-Iraqi Board for Medical Specializations, Department of Dermatology \& \\ Venereology, College of Medicine, University of Baghdad, Baghdad, Iraq; ${ }^{2}$ Department of Dermatology \& Venereology, College of \\ Medicine, University of Baghdad, Baghdad, Iraq; ${ }^{3}$ Department of Dermatology \& Venereology, Baghdad Teaching Hospital, Bagh- \\ dad, Iraq. \\ Email: "ksharquie@ymail.com, adilnoaimi@yahoo.com, Entesar.salih78@yahoo.com
}

Received September $4^{\text {th }}, 2013$; revised October $2^{\text {nd }}, 2013$; accepted October $10^{\text {th }}, 2013$

Copyright (C) 2013 Khalifa E. Sharquie et al. This is an open access article distributed under the Creative Commons Attribution License, which permits unrestricted use, distribution, and reproduction in any medium, provided the original work is properly cited.

\begin{abstract}
Background: The pathogenesis of acne vulgaris is multifactorial, and therapy can be directed at many of these factors, singly or in combination. There are different modalities of treatment of active acne vulgaris but they are often long lasting which could not be accepted by many patients. Objective: To evaluate the effectiveness, long term efficacy and safety of chemical peeling using 35\% TCA solution in the treatment of active acne vulgaris. Patients and Methods: This clinical, interventional, therapeutic study was done at the Department of Dermatology-Baghdad Teaching Hospital during the period from January 2012 to March 2013. Eighteen patients with active acne vulgaris were included in this study, $10(55.6 \%)$ females and $8(44.4 \%)$ males. Their ages ranged from 15 to 35 (21.56 \pm 5.501$)$ years. Twelve patients were associated with acne scars. History and dermatological examination were performed for all patients regarding all demographic points related to the disease. Chemical peeling with $35 \%$ TCA used one session regarding active acne vulgaris and three sessions in patients with associated scarring. Scoring for active acne vulgaris and acne scar was done for each case before and after peeling to evaluate the severity of acne lesions and scarring. All patients were with Fitzpatrick's skin types III and IV. Patients were followed up every two weeks for 12 weeks after starting therapy and every 4 weeks for 12 weeks after stopping the treatment to watch improvement, side effects and relapse. Results: Scoring for active acne vulgaris including papules and pustules showed highly statistically significant reduction after 2 weeks of therapy $(p<0.0001)$, while in the acne scar scoring reduction ranged from $26 \%$ to $50 \%$ in 2 patients and $50 \%$ to $75 \%$ in 2 patients while more than $75 \%$ in 8 patients were with statistically significant reduction $(p=0.000002)$. All patients had full satisfaction with the results of operation. Post inflammatory hyperpigmentation was observed in two patients few weeks after peeling but follow-up showed complete clearance of pigmentation with lightening and tightening of skin. No relapse of active lesion was recorded after twelve weeks follow-up. Conclusions: Chemical peeling by TCA $35 \%$ is a cost-effective mode of therapy for active acne vulgaris and acne scar with low down time in patients with dark complexion.
\end{abstract}

Keywords: Chemical Peeling; TCA; Active Acne Vulgaris; Acne Scarring; Dark Complexion

\section{Introduction}

Acne is a common chronic inflammatory skin disease experienced by most adolescents and young adults. The pathogenesis of acne vulgaris is multifactorial. The four major identified factors that are involved in pathogenesis of active acne lesion formation and scarring are as follows: excess sebum production, follicular epidermal hyperk-

*Disclosure: this study is an independent study and not funded by any drug company.

\#Corresponding author. eratinization, the proinflammatory effects of propioni bacterium acnes and other normal skin floras, and immunological reactions [1,2].

Although there are many topical and systemic agents that have been used in treatment of acne vulgaris, still many patients don't use these therapies and are considered as poor compliance, other patients have no time to use drugs or they don't like to use them or they have phobia from side effects [3-8]. But acne vulgaris is one of the cosmetic major problems among the youth and 
often needs long term therapy because it might often end with complications like scarring [9-12].

Lasers have been used in treatment of active acne vulgaris but there is controversy regarding their effectiveness as one study showed using Diode laser is an effective therapy in clearing lesions using three sessions, two weeks apart, and another study using Pulse Dye Laser (PDL) showed clearance of inflammatory acne vulgaris lesions using one session. While another study also using Diode laser didn't show significant improvement of facial acne [13-15].

As lasers are expensive therapy, have controversial result and are not available in all centers, accordingly we are looking for a simple available and less costly mode of therapy than laser, which could be used in treatment of active acne vulgaris like using acids as peeling agents $[16,17]$.

Accordingly the present work was arranged to use $35 \%$ trichloracetic acid (TCA) as a peeling agent in treatment of all severity grades of active acne vulgaris with or without scarring in dark skinned patients.

\section{Patients and Methods}

This clinical, interventional, therapeutic study was carried out in the Department of Dermatology and Venereology-Baghdad Teaching Hospital during the period from January 2012 to March 2013.

Eighteen patients were included in this study, 10 $(55.6 \%)$ females and $8(44.4 \%)$ males. Their ages ranged from 15 - 35 with mean and SD of $21.56 \pm 5.501$ years with active acne vulgaris, while twelve patients had associated acne scars $8(66.7 \%)$ females and $4(33.3 \%)$ males.

The nature and target of this study were explained for each patient and formal consent was taken for each patient before starting the therapy, after full explanation about the nature of the disease, course, the procedure of treatment, follow up, prognosis and the need for pre and post treatment photographs by Sony-Digital, high sensitivity, 16.1 megapixels, $5 \times$ optical zoom camera in the same place with fixed illumination and distance. Also, ethical approval was given by the scientific committee of the Scientific Council of Dermatology and VenereologyIraqi Board for Medical Specializations. Statistical analysis was carried out using $\mathrm{T}$ test and Chi square.

The severity of acne was graded using the following score:

- Mild acne in which the count of pustules is less than 20 and the count of papules is less than 10 .

- Moderate acne in which the count of pustules is ranging between 20 - 40 and the count of papules is ranging between 10 - 30 .

- Severe acne in which the count of pustules is more than 40 and the count of papules is more than 30 .

Patients who had scarring in addition to active lesions the following score were used to evaluate the severity of scarring:
Score $0=0$
Score $1=1 \%-25 \%$
Score $2=26 \%-50 \%$
Score $3=51 \%-75 \%$
NO change or baseline.
Mild reduction.
Moderate reduction.
Marked reduction.
Score $4>75 \%-100 \%$
Excellent reduction.

Patients satisfaction to response to therapy was evaluated as follow: satisfaction of patients to treatment is classified into:

1) Full satisfaction.

2) Partial satisfaction.

3) No satisfaction.

In addition to active lesions, four patients had white and black comedones. All patients were with Fitzpatrick's skin types III and IV.

The exclusion criteria are coexistence of: any other dermatoses involving the face and allergy to medications, plus patients who had used any topical and systemic treatments in the previous one month, pregnant and lactating women. Also, history of recurrent herpes simplex infection, immune compromised patients, diseases or drugs interfere with clotting systems, patients with medical diseases like diabetes mellitus, epilepsy and patients with other types of acne like drug induced acne, cosmetic acne, post-hair epilation acne, occupational acne, perioral dermatitis, mechanical acne, and acne aestivalis were excluded.

A solution of trichloracetic acid (TCA) 35\% consisted of $35 \mathrm{~g}$ (United States Pharmacopeia, USP, crystals) in $100 \mathrm{ml}$ of distilled water was prepared and kept in amber glass bottles to be ready for use.

Patients were prepared by cleansing and degreasing the whole face by using acetone or $70 \%$ alcohol, then the whole face was coated with TCA until get frost by a wrung-out $4 \times 4$ gauze is generally rubbed in with pressure, and number of coating ranged from 1 - 3 applications with mean 2 until uniform frosting occurred. Cold wet compresses are applied immediately after the peel. Patients are told that stinging will crescendo for $2 \mathrm{~min}$ utes and then subsides. Topical and systemic antibiotic with antihistamine are prescribe for patients and asked the patients to wash the face $3-6$ times/day with potassium permanganate solution $(1 / 10000)$ in the first five days following peeling, and after five days advised the patients to use sun screen at morning and topical hydrocortisone at night and all patients were seen after 2 weeks and every 2 weeks for 3 months and then monthly for three months to report the improvement, side effects and relapse.

\section{Results}

TCA peeling was used once regarding active acne lesions and three times in patients with associated scarring.

Scoring for active acne vulgaris included papules and 
pustules showed statistically significant reduction after 2 weeks $(P$-value $<0.0001)$ following peeling (Table 1, Figure 1).

The acne scar scoring reduction was ranged from $26 \%$ - 50\% in 2 patients (moderate reduction) and 50\% - 75\% in 2 patients (marked reduction) while was more than $75 \%$ in 8 patients (excellent reduction).

TCA peeling for scarring was used three times 2 weeks apart and there months of follow up after peeling, was obvious reduction response after $1^{\text {st }}$ session but was marked reduction after third session with statistically significant reduction $(P$-value $=0.000002)$ following peeling as illustrated in the Table 2 (Figure 2).

Also, there was clearance of comedones in four patients. All patients were fully satisfied regarding response to therapy. Follow up for three months after peeling showed no relapse in active acne vulgaris and the reduction in scarring was permanent.

Post inflammatory hyperpigmentation was observed few weeks after peeling in two patients following three sessions of peeling but follow up for 3 months showed complete clearance of pigmentation with lightening and tightening of skin.

\section{Discussion}

There are many therapies for active acne vulgaris but all of these need long term of treatment, at least 6 months and the main aim of therapy is to prevent or minimize scarring [2-6]. Still there are many non compliant patients for many reasons mainly because they are not ready to use treatment for long time or they are afraid from their side effects. Accordingly researcher are look-

Table 1. Showing patients with active acne vulgaris that treated by $35 \%$ TCA peels.

\begin{tabular}{|c|c|c|c|c|c|}
\hline \multicolumn{2}{|c|}{ Parameters } & \multirow{2}{*}{$\frac{1^{\text {st }} \text { Visit }}{44.72}$} & \multirow{2}{*}{$\frac{2^{\text {nd }} \text { Visit }}{11.78}$} & \multirow{2}{*}{$\frac{3^{\text {rd }} \text { Visit }}{2.50}$} & \multirow[t]{2}{*}{$\begin{array}{c}\text { Percent } \\
\text { Reduction }\end{array}$} \\
\hline & Mean & & & & \\
\hline \multirow[t]{3}{*}{ Papules } & SD & 29.63 & 9.21 & 1.98 & $94.4 \%$ \\
\hline & ${ }^{*} P$-value & & $>0.0001$ & $>0.0001$ & \\
\hline & Mean & 46.06 & 21.89 & 2.83 & \\
\hline \multirow[t]{2}{*}{ Pustules } & $\mathrm{SD}$ & 25.701 & 14.54 & 2.0 & $93.86 \%$ \\
\hline & ${ }^{*} P$-value & & $>0.0001$ & $>0.0001$ & \\
\hline
\end{tabular}

${ }^{*}$ Percent Reduction $=(\mathrm{A}-\mathrm{B}) / \mathrm{A} \times 100, \mathrm{~A}$ is an initial value, $\mathrm{B}$ is a final value.

Table 2. Showing patients with active acne vulgaris with associated scarring treated by $35 \%$ TCA peels.

\begin{tabular}{cccc}
\hline Reduction Rate & $\begin{array}{c}\text { No. of } \\
\text { Patients }\end{array}$ & $\begin{array}{c}\text { Percent } \\
\text { Reduction }\end{array}$ & ${ }^{*} P$-value \\
\hline Moderate Reduction $26 \%-50 \%$ & 2 & 16.7 & \\
Marked Reduction $51 \%-75 \%$ & 2 & 16.7 & ${ }^{*} 0.000002$ \\
Excellent Reduction $75 \%-100 \%$ & 8 & 66.7 & \\
Total & 12 & 100.0 & \\
\hline
\end{tabular}

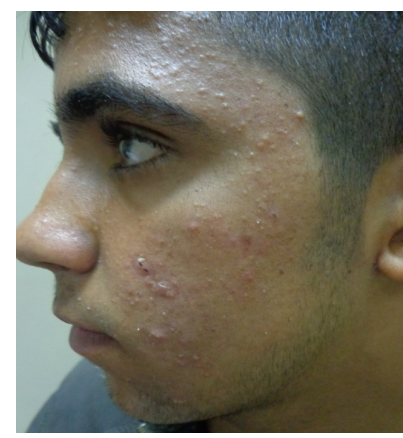

(a)

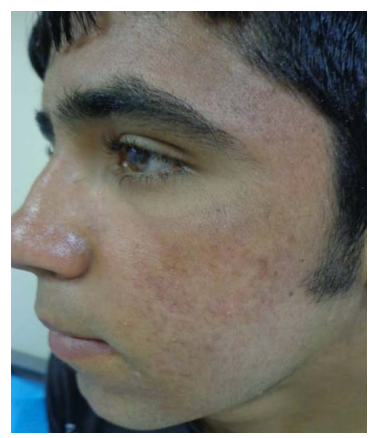

(b)
Figure 1. Eighteen years old male with active skin lesions. (a) Before treatment; (b) Showing clearance of active lesions after $35 \%$ TCA peels.

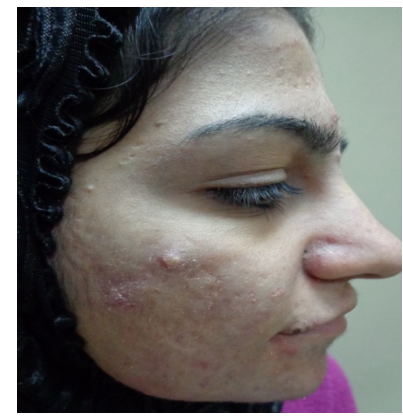

(a)

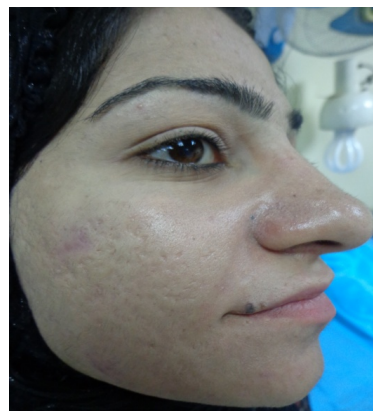

(b)
Figure 2. Twenty three years old female patient. (a) Showing active acne lesions, comedones and scarring; (b) The same patient showing clearance of active lesion and reduction of scarring following three peels using 35\%TCA.

ing for single therapy that used over short time in order to induce recovery from active lesions and prevent scarring $[7,8]$.

Lasers have been used effectively in treatment of acne vulgaris using Diode and PDL using one or three sessions of laser but there is one study using PDL showed no significant improvement of facial acne using single session [13-15].

The present work using 35\% TCA showed significant improvement of active acne vulgaris including papules and pustules after one session of peeling while patient with active acne lesion and scarring showed marked clearance in active lesion and scarring.

Hence the present study is very cost effective with low down time using one session of TCA that encouraged non compliant patients especially associated with scarring to have therapy that cleared their lesions without complications.

Dermabrasion and peeling by lasers or acids are not well advised in patients with dark complexion as post inflammatory hyperpigmentation might be one of the complications of these therapies. But we have noticed that from daily clinically practice that postinflammatory hy- 
perpigmentation is not a complication of dermabrasion or peeling although all our patients have Fitzpatrick's skin types III and IV. In contrary, these patients will have whitening and tightening of their skin [18,19]. This is an agreement with present work as only two patients had postinflammatory hyperpigmentation that resolved over time.

It is difficult to explain the mechanism of action of TCA peeling but we can speculate it works through the following mechanisms: might change the microflora of skin by reduction number of bacteria mainly Propioni bacterium acnes and other bacteria that causing acne, also might reduce the size of sebaceous glands that's involved in acne pathogenesis \& thirdly might change the immunological reaction involved in the acne formation and scarring.

\section{Conclusion}

In conclusion, the present study strongly recommend using TCA 35\% peeling in treatment of active acne vulgaris as a new cost-effective mode of with low-down time especially cases associated with scarring and in noncompliant patients with medical therapy.

\section{REFERENCES}

[1] J. William and P. M. Harald, "Acne Diagnosis and Management," Martin Dunitz Ltd., London, 2001, pp. 1-37.

[2] S. Sommkr, R. Bojar, W. J. Cunliffe, D. Hollanixf, K. T. Holland and H. Naags, "Investigation of the Mechanism of Action of 2\% Fucidic Acid Lotion in the Treatment of Acne Vulgaris," Clinical and Experimental Dermatology, Vol. 22, No. 5, 1997, pp. 211-215. http://dx.doi.org/10.1111/j.1365-2230.1997.tb01070.x

[3] C. Ellis and K. Krach, "Uses and Complications of Isotretinoin Therapy," Journal of the American Academy of Dermatology, Vol. 45, No. 5, 2001, pp. S150-S157. http://dx.doi.org/10.1067/mjd.2001.113717

[4] J. Leyden, "Current Issues in Antimicrobial Therapy for the Treatment of Acne," Journal of the European Academy of Dermatology and Venereology, Vol. 15, Suppl. 3, 2001, pp. 51-55.

http://dx.doi.org/10.1046/j.0926-9959.2001.00013.x

[5] E. Eaden, C. Jones, J. Tipper, J. Cove, W. Cunliffe and A. Layton, "Antibiotic Resistant Propioni bacteria in Acne: Need for Policies to Modify Antibiotic Usage," British Medical Journal, Vol. 306, No. 6877, 1993, pp. 555-556. http://dx.doi.org/10.1136/bmj.306.6877.555

[6] J. Leyden and A. Shalita, "Rational Therapy for Acne Vulgaris: An Update on Topical Treatment," Journal of the American Academy of Dermatology, Vol. 15, No. 4, 1986, pp. 907-914. http://dx.doi.org/10.1016/S0190-9622(86)70250-8

[7] E. A. Eady, J. H. Cove, K. T. Holland and W. J. Cunliffe, "Erythromycin Resistant Propioni bacteria in Antibiotic Treated Acne Patients: Association with Therapeutic Fail- ure,” British Journal of Dermatology, Vol. 121, 1989, pp. 51-57.

http://dx.doi.org/10.1111/j.1365-2133.1989.tb01399.x

[8] J. J. Leyden, K. J. McGinley, S. Cavalieri, G. F. Webster, O. H. Mills and A. M. Kligman, "Propioni bacterium acnes Resistance to Antibiotics in Acne Patients," Journal American Academy of Dermatology, Vol. 8, No. 1, 1983, pp. 41-45. http://dx.doi.org/10.1016/S0190-9622(83)70005-8

[9] A. L. Zaenglein and D. M. Thibouto, "Acne Vulgaris," J. L. Bolognia, J. L. Jorizzo and J. V. Schaffer, Eds., Dermatology, 3rd Edition, Elsevier Saunders Company, Amsterdam, 2012, pp. 545-560.

[10] W. D. James, T. G. Berger and D. M. Eleston, Eds., "Acne: Andrew's Diseases of the Skin Clinical Dermatology," 11th Edition, Saunders Company Elsevier, Philadilphia, 2011, pp. 228-246.

[11] C. I. Jacob, J. S. Dover and M. S. Kaminer, “Acne Scarring: A Classification System and Review of Treatment Options," Journal of the American Academy of Dermatology, Vol. 45, No. 1, 2001, pp. 109-117. http://dx.doi.org/10.1067/mjd.2001.113451

[12] D. L. Moritz, "Surgical Corrections of Acne Scars," Dermatology Nursing, Vol. 4, 1992, pp. 291-299.

[13] E. D. Seaton, A. Charakida, P. E. Mouser, I. Grace, R. M. Clement and A. C. Chu, "Pulsed-Dye Laser Treatment for Inflammatory Acne Vulgaris: Randomized Controlled Trial," Lancet, Vol. 362, No. 9393, 2003, pp. 1347-1352. http://dx.doi.org/10.1016/S0140-6736(03)14629-6

[14] J. S. Orringer, S. Kang, T. Hamilton, W. Schumacher, S. Cho, C. Hammerberg, G. J. Fisher, D. J. Karimipour, T. M. Johnson and J. J. Voorhees, "Treatment of Acne Vulgaris with a Pulsed Dye Laser: A Randomized Controlled Trial," Journal of the American Medical Association, Vol. 291, No. 23, 2004, pp. 2834-2839. http://dx.doi.org/10.1001/jama.291.23.2834

[15] P. M. Friedman, M. H. Jih, A. K. Asadi and L. H. Goldberg, "Treatment of Inflammatory Facial Acne Vulgaris with 1450-nm Diode Laser: A Pilot Study," Dermatologic Surgery, Vol. 30, No. 2, 2004, pp. 147-151. http://dx.doi.org/10.1111/j.1524-4725.2004.30062.x

[16] V. K. Garg, M. S. Sinha, and R. Sarkar, "Glycolic Acid Peels versus Salicylic-Mandelic Acid Peels in Active Acne Vulgaris and Post-Acne Scarring and Hyperpigmentation: A Comparative Study," Dermatologic Surgery, Vol. 35, No. 1, 2009, pp. 59-65. http://dx.doi.org/10.1111/j.1524-4725.2008.34383.x

[17] L. Atzori, M. A. Brundu, P. Biggio and A. Orru, "Glycolic Acid Peeling in the Treatment of Acne," Journal of the European Academy of Dermatology and Venereology, Vol. 12, No. 2, 1999, pp. 119-122. http://dx.doi.org/10.1111/j.1468-3083.1999.tb01000.x

[18] M. M. Al-Waiz and A. I. Al-Sharqi, "Medium Depth Chemical Peels in Treatment of Acne Scars in Dark Skinned Individuals," Dermatologic Surgery, Vol. 28, No. 5, 2002, pp. 383-387. http://dx.doi.org/10.1046/j.1524-4725.2002.01081.x

[19] K. E. Sharquiek and A. A. Noaimi, " $\mathrm{CO}_{2}$ Dermabrasion of Acne Scarring," Iraqi Journal of Community Medicine, Vol. 25, 2013, in Press. 